\title{
Targeting HER2 Positive Breast Cancer with Chemopreventive Agents
}

\author{
Joseph Wahler ${ }^{1}$ Nanjoo Suh ${ }^{1,2}$
}

Published online: 19 April 2015

(C) Springer International Publishing AG 2015

\begin{abstract}
Human epidermal growth factor receptor 2positive (HER2+) breast cancer is a subtype of breast cancer that is exhibited in approximately $20-30 \%$ of breast cancer cases. The overexpression of HER2 is typically associated with a more aggressive disease and poor prognosis. Currently, the therapeutic drugs trastuzumab and lapatinib are the most commonly used to combat HER2+ breast cancer. However, tumors can develop resistance to these drugs. A better understanding of the mechanism of how HER2+ breast cancer works will help aid the development for new therapeutic approaches which more closely target the source of the signaling dysfunction. This review summarizes four major points in the context of HER2 overexpressing breast cancer (i) HER2 as a molecular target in breast cancer therapy, (ii) current treatment options as well as ongoing clinical studies, (iii) animal and cellular models for the study of HER2 overexpressing breast cancer, and (iv) future therapies and chemopreventive agents used to target HER 2+ breast cancer.
\end{abstract}

Keywords HER2 - Breast cancer · Triterpenoids · Rexinoids $\cdot$ Vitamin D compounds $\cdot$ Vitamin E

This article is part of the Topical Collection on Cancer Chemoprevention

Nanjoo Suh

nsuh@pharmacy.rutgers.edu

1 Department of Chemical Biology, Ernest Mario School of Pharmacy, Rutgers, The State University of New Jersey, 164 Frelinghuysen Road, Piscataway, NJ 08854, USA

2 Rutgers Cancer Institute of New Jersey, New Brunswick, NJ, USA

\section{Introduction}

Despite advances in the prevention and treatment of breast cancer, it still remains the most commonly diagnosed female malignancy [1]. Breast cancer is a heterogeneous disease and is typically classified based upon the expression of three different receptors, the estrogen receptor, progesterone receptor, and human epidermal growth factor receptor 2 (HER2) [2]. HER 2 amplification has been implicated in approximately 20 to $30 \%$ of human breast cancer cases [3]. HER2, also known as ErbB2 or $n e u$, is a $185-\mathrm{kDa}$ transmembrane glycoprotein receptor tyrosine kinase. HER2 is part of the epidermal growth factor receptor (EGFR/ErbB/HER1) family of growth factor receptors. Four members of the ErbB family, HER1 (EGFR), HER2 (ErbB2/neu), HER3 (ErbB3), and HER4 (ErbB4) dimerize in various combinations to activate signaling pathways which regulate cell growth, survival, and differentiation $[4,5]$. The overexpression of HER2 leads to enhanced and prolonged signaling of these pathways, ultimately initiating antiapoptotic and cell proliferation signals in breast cancer $[4,6]$.

The first line of treatment for breast cancer has long been radiation, surgery, and chemotherapy [7]. However, targeting HER2 and its pathways in treatment has improved the outcomes in breast cancer patients $[8,9]$. Currently, there are several treatment options specific to HER2+ breast cancer such as the monoclonal antibodies, trastuzumab and pertuzumab, and the dual tyrosine kinase inhibitor, lapatinib $[8,10,11]$. Despite the more targeted therapies, resistance to these drugs has been a major challenge to effectively treat HER $2+$ breast cancer $[12,13]$. With increased efforts, new approaches and chemopreventive strategies targeting HER2+ breast cancer have emerged. These studies have led to promising therapies in the preclinical and clinical stages of development. 
There are various HER2+ breast cancer cell lines and animal models that are used to test existing therapies, novel therapeutic approaches, and chemopreventive agents. The two most common HER2 breast cancer cell lines utilized are BT474 and SK-BR-3 cell lines [14]. These cell lines are commonly used in xenograft animal systems along with the transgenic mouse mammary tumor virus (MMTV)/neu HER2overexpressing mouse model [15]. These tools will be invaluable in the accelerated screening and testing of new compounds for HER2 targeted therapies. Over the past 25 years, the HER2 receptor has become of utmost importance for the development of therapeutic approaches to a common breast cancer subtype. Despite development in the field, resistance has emerged to existing therapies. This has called for novel therapies and chemopreventive strategies to effectively combat HER2+ breast cancer.

\section{HER Signaling}

The HER receptors are composed of three general domains: the extracellular domain to which ligands bind, the transmembrane domain which anchors the receptor in the membrane, and the intracellular tyrosine kinase domain involved in signal transduction [16]. The HER2 receptor can homo- and heterodimerize with other members of the HER family such as HER1, HER3, and HER4 [17-20]. The structural conformation of HER 2 is very different than that of other HER family members. HER2 is unable to bind ligands and is in a constitutively activated conformation in which the extracellular domain is capable of dimerization with other receptors $[16,21]$. Since HER2 is capable of dimerization, even in the absence of ligand, this provides some insight as to why HER2 is the preferred dimerization partner for other HER receptors [16, 22, 23]. On the contrary, the HER 3 receptor has unique characteristics in that it has little to no intrinsic kinase activity [24, 25]. Despite this, HER3 is still capable of ligand binding and heterodimerization, at which time downstream signaling can be activated by intrinsic kinase activity from its dimerization partner [26]. Upon dimerization, the intrinsic kinase activity is activated, and tyrosine residues within the cytoplasmic tails of the receptors are phosphorylated. This phosphorylation event initiates intracellular signaling cascades [7, 27, 28].

There are three dimers that regulate signaling in HER2 overexpressing breast cancer, HER1/HER2, HER2/HER2, and HER2/HER3. Thus, increased HER2 expression leads to increased dimerization and a deregulation of downstream signaling. The signaling cascades that these dimers activate are involved in a diverse range of cellular processes such as cell growth, proliferation, survival, differentiation, invasion, and angiogenesis $[5,9,29,30]$. Two major pathways that regulate these cellular processes are the Ras/Raf/MEK/MAPK cascade as well as induction of the phosphatidylinositol 3-kinase (PI3K)/Akt pathway which in turn activates the NF-kB pathway $[5,31]$. The combination of these signaling cascades allows HER2+ breast cancer to continue to proliferate as well as evade apoptosis [32, 33].

These receptors and pathways have become primary targets for current treatments as well as new therapeutics. The reason HER receptors and signaling have become such crucial targets is due to the overexpression of HER2, the primary dimerization partner of the HER receptors, in a large percentage of breast cancers. The HER2 signaling output deregulates cell proliferation, differentiation, and survival, which is the driving force of the growth and metastases of breast cancer. The inhibition of these receptors and their signaling pathways provides a strong approach to the treatment of the HER2 subtype of breast cancer, which could increase patient survival and decrease the chance of relapse.

\section{Approved HER2 Positive Breast Cancer Therapies and Ongoing Clinical Trials}

Currently, there are several treatment options targeting the HER2 receptor or its associated signaling pathways, ultimately leading to longer survival and improved patient outcome. Approved HER2 treatment options include monoclonal antibodies, small molecule RTK inhibitors, and the combination of these drugs with other chemotherapeutic agents. Drugs that are FDA approved and in ongoing clinical trials for HER2+ breast cancer are summarized in Table 1.

\section{Trastuzumab}

Trastuzumab, a monoclonal antibody which targets the HER2 receptor, was developed by Ullrich, Shepard, and Fendly at Genentech who developed murine antibodies against ErbB2 [34]. One of the more promising antibodies, 4D5, showed anti-proliferative effects in breast tumor cell lines [35]. This 4D5 antibody was humanized to be tested clinically [36], leading to the 1998 approval of trastuzumab (Herceptin, Genentech) [9] and provided one of the first drugs for metastatic breast cancer $[17,37]$. The antibody targets the extracellular domain IV of the HER2 receptor [38]. This inhibits dimerization to other HER family members, hence blocking signaling pathways associated with HER receptor activation.

Trastuzumab works on a variety of pathways and several mechanisms of action have been elucidated in vitro. Trastuzumab has been shown to downregulate cyclin D1 and increase p27 levels, leading to inhibition of Cdk2 and cell proliferation in HER2 overexpressing cell lines, BT-474 and SK-BR-3 [39]. Inhibition of HER3 phosphorylation, disrupting PI3K activation and Akt phosphorylation, has also been demonstrated with trastuzumab in vitro $[39,40]$. Another mechanism of trastuzumab activity involves the inhibition of HER2 cleavage and the suppression of enhanced intracellular signaling through p95HER2 [41]. Despite preclinical work 


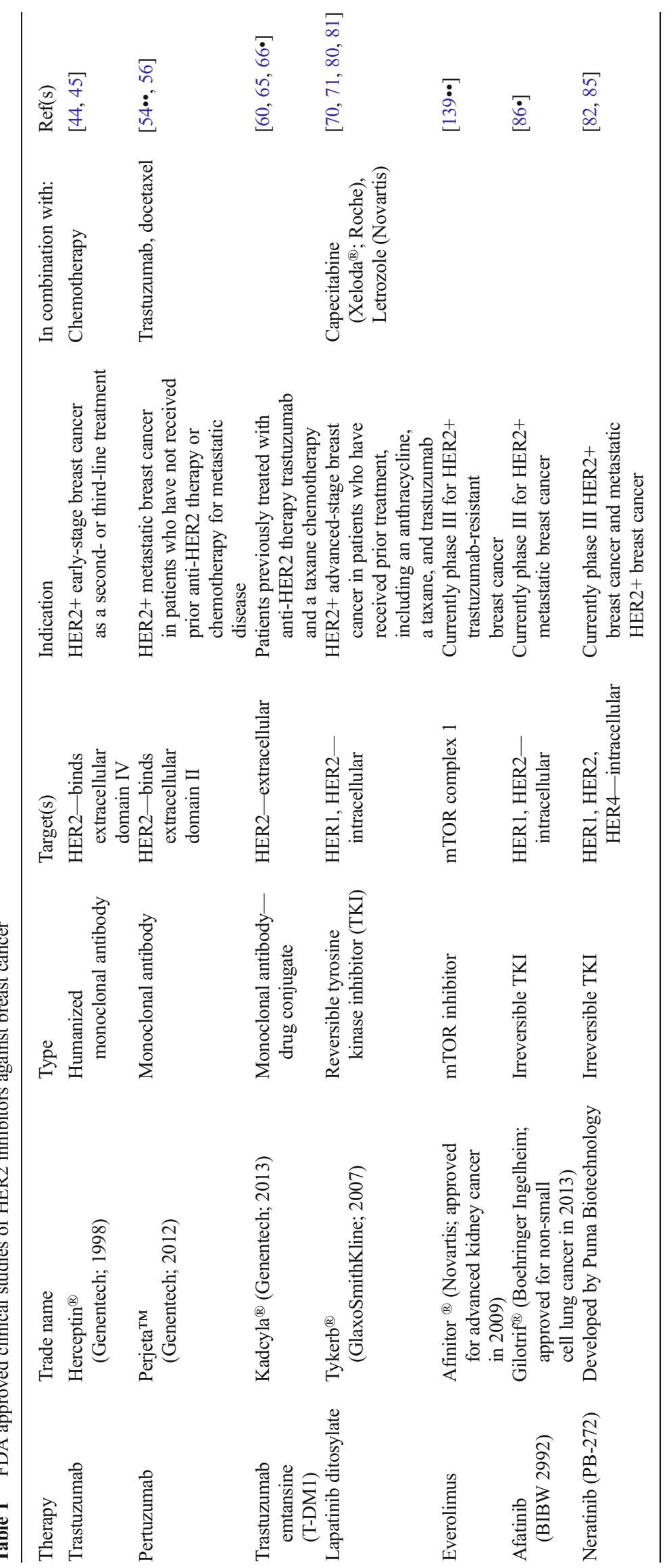


shown in cell and animal models, mechanisms of trastuzumab action in human patients are much less understood.

In primary breast tumors, treatment with trastuzumab showed high levels of apoptosis and a decrease in the levels of nuclear phosphorylated Akt [42]. Serum taken from patients treated with trastuzumab showed a decrease in HER2 extracellular domain concentrations, suggesting that trastuzumab inhibits cleavage of HER2 in a clinical setting [43]. Trastuzumab as an adjuvant to chemotherapy showed an increased latency to disease progression, a more effective and prolonged response to chemotherapy and improved overall survival compared to chemotherapy alone $[17,44,45]$. Currently, trastuzumab is the only approved adjuvant treatment for early-stage HER2+ breast cancer [31]. Trastuzumab is also used against metastatic HER2+ breast cancer alone [46] or in combination with paclitaxel $[17,47]$ or docetaxel [48, 49]. Despite the multimechanistic approach of trastuzumab and improved survival in patients, resistance has emerged and disease progression has become a clinical problem $[13,50]$.

\section{Pertuzumab}

Pertuzumab (Perjeta; Genentech), recently approved in 2012, is an antibody against the extracellular domain II of HER2 which disrupts dimerization of HER2 with other HER family members [51]. Pertuzumab is slightly different than trastuzumab in the fact that it targets domain II of HER2, while trastuzumab targets domain IV of the HER2 receptor [51]. It has been specifically shown to block dimerization with the ligand-bound form of HER3 [52]. Treatment with pertuzumab has shown to downregulate PI3K/Akt and MAPK pathways leading to antiproliferative effects in tumors [10, 51-53]. Early studies in vitro showed that pertuzumab in combination with trastuzumab resulted in decreased cell survival of HER2 breast cancer cells, partially due to apoptotic effects [10]. The combination treatment also enhanced antitumor activity in a xenograft model of HER2-overexpressing cells [53]. Currently, pertuzumab is approved in combination with trastuzumab and docetaxel [54••]. It is being evaluated for use with chemotherapy in trastuzumab-relapsed HER2 breast cancer patients [55-58]. There are also ongoing clinical trials to test pertuzumab in combination with a drug recently approved in early 2013, trastuzumab emtansine (T-DM1) [59].

\section{Trastuzumab Emtansine}

Trastuzumab emtansine (T-DM1; Genentech) is an antibody drug conjugate consisting of the antibody trastuzumab bound to the microtubule binder, mertansine $[60,61]$. This drug provides two effects; the inhibition of HER2-mediated signaling, as well as the cytotoxicity provided by mertansine when it enters the cells, binds tubulin, and causes cell death [62•]. This drug conjugate retains the mechanisms of tumor inhibition of trastuzumab, while delivering a cytotoxic agent more specifically to the cancer-causing cells [63]. Early studies of T-DM1 in HER2+ models show effective antitumor activity in trastuzumab- or lapatinib-resistant cells and xenograft $[60,63]$. Recent studies also show that T-DM1 can improve the targeting of the $\mathrm{CD} 44^{\text {high }} \mathrm{CD} 24^{\text {low }}$ tumor-initiating cell subset [64••]. T-DM1 is approved for metastatic breast cancer in patients who have previously been treated with a trastuzumab and a taxane or in patients that show tumor recurrence $[65,66 \bullet$.

\section{Lapatinib}

Lapatinib (Tykerb, GlaxoSmithKline) is a reversible dual tyrosine kinase inhibitor of both HER1 and HER2 [67, 68]. The drug was initially approved for advanced stage HER2overexpressing breast cancer for use in combination with capecitabine for patients who experienced disease progression with prior therapy $[9,69,70]$. In 2010, lapatinib was approved for use in combination with letrozole specifically for postmenopausal women with HER2 and hormone receptor-positive breast cancer $[71,72]$. Lapatinib is also used as a second line of defense to trastuzumab in patients that do not respond well to trastuzumab therapy [73].

Lapatinib binds specifically to the adenosine triphosphate (ATP)-binding pocket of the HER1 and HER2 kinase domains and prevents phosphorylation and receptor activation [68]. In turn, the activation of downstream signaling pathways such as the MAPK and PI3K/Akt pathways is inhibited in breast cancer cells, thus reducing tumor growth and proliferation [74-76]. Lapatinib also enhances the apoptotic effects of trastuzumab when used in combination in vitro $[75,77,78]$.

This data has led to clinical studies to test the effects of lapatinib in combination with trastuzumab to treat advanced HER2+ breast cancer that has no responded to trastuzumab $[75,79]$. The theory behind this combinatorial approach is due to the different mechanisms of action in how these drugs work. Trastuzumab is a monoclonal antibody, which prevents the HER2 receptor from dimerizing, and lapatinib is a tyrosine kinase inhibitor, which will prevent nascent signaling through the HER dimers. Another benefit is that, unlike trastuzumab, lapatinib is a small molecule; therefore, it is better suited to penetrate the central nervous system (CNS) and has the potential to better control an advanced, metastatic breast cancer [31].

There are several major phase III clinical trials involving lapatinib that are currently underway, TEACH (Tykerb Evaluation After Chemotherapy) and NeoALTTO (Neoadjuvant Lapatinib and/or Trastuzumab Treatment Optimization) [80, 81]. These studies will pave the way for approved use of lapatinib and trastuzumab in combination as an alternative treatment option for HER2+ breast cancer patients. 


\section{Neratinib}

Neratinib (PB-272; Puma Biotechnology) is a dual tyrosine kinase inhibitor of HER1, HER2, and HER4 under investigation for the treatment of early- and late-stage HER $2+$ breast cancer $[82,83]$. Neratinib is an irreversible tyrosine kinase inhibitor, unlike the reversible nature of lapatinib; this drug will covalently bind to the ATP pocket of the receptor kinase [83]. Cell cycle arrest as well antiproliferative effects correlate with the decrease seen in signaling in the HER2 model systems upon treatment with neratinib [83]. Neratinib showed promising growth inhibitory results in trastuzumab resistant cell lines as well as in HER2+ xenograft in vivo [84•]. There are a variety of clinical studies underway to test the effects of neratinib as a first-line treatment as well as treatment for relapsed or trastuzumab-resistant HER2 breast cancer both as a monotherapy and in combination with a multitude of other cytotoxic agents [85].

\section{Afatinib}

Afatinib (BIBW 2992; Boehringer Ingelheim), like neratinib, is a small-molecule irreversible tyrosine kinase inhibitor of HER family members in HER2+ breast cancer [86•]. Afatinib has recently completed a phase II study showing the beneficial effects in HER2+ breast cancer that has escaped trastuzumab treatment [86•]. Afatinib has also recently been assessed in a phase I study in combination with trastuzumab for patients with advanced or metastatic HER2+ breast cancer; however, this study warranted further investigation due to inconclusive results [87].

\section{Preclinical HER2 Experimental Models}

The development of novel HER2+ breast cancer therapy is an arduous process with the end goal of the therapy reaching clinical trials and making it to the market. There is a long road of optimization to achieve effective target inhibition, while maintaining safety and reducing the potential for drug resistance. There is a vast array of established cell lines and animal models available for the assessment and optimization of potential HER2 therapies.

In vitro HER 2 models Two of the most common HER2+ cell lines that are used in drug screening are BT-474 and SK-BR-3. These cell lines have been utilized in the development of current drugs such as lapatinib and trastuzumab [7, 14]. Although both cell lines show HER2 overexpression, the BT-474 line shows lower levels of the other HER receptors and the SKBR-3 line shows an increased level of HER1 (EGFR) [88]. Other notable cell lines that have been tested and have shown resistance to trastuzumab treatment are MDA-MB-453, SUM-
190, SUM-185, SUM-206, SUM-225, HCC1569, and JIMT1 cell lines [89-91]. These cell lines have a specific role for future research that could counteract current resistance to trastuzumab. Common HER2+ cell lines such as SK-BR-3, BT-474, and MDA-MB-361 have been conditioned with trastuzumab and lapatinib in a cell culture to create resistant cell lines to test new drug candidates that can overcome this resistance $[63,75]$.

In vivo HER 2 models The most commonly used mouse model for the study of HER2+ breast cancer is the mouse mammary tumor virus (MMTV)-HER2/neu model (also known as MMTV-ErbB2 model) [92, 93]. This is a transgenic mouse model that overexpresses the active form of the rat oncogene, neu (the rat homologue of HER2) [92, 93]. The tumors that form in this model system resemble human ductal carcinoma in situ (DCIS) and are typically estrogen receptor negative and hormone independent $[94,95]$. Since the MMTV-HER2/neu model represents a common subset of breast cancer, it has been extensively utilized for cancer treatment and prevention studies. Another commonly used transgenic model is the FVB/n Tg (MMTV-PyVmT) mouse. This model utilizes a HER2 mimic, which resembles the effect of HER2 heterodimers in a ligand- and dimerization-independent manner. This is an extremely efficient model showing $100 \%$ penetrance, in which tumors form around 20 weeks of age. Lung metastases also appear in this model.

\section{Experimental Therapeutic Approaches for HER2+ Breast Cancer}

Despite advancements in HER2+ targeted therapies, resistance and disease progression have become clinical problems with current treatments, such as lapatinib and trastuzumab. Therefore, there is a variety of preclinical work investigating the effects of chemopreventive compounds on HER2+ breast cancer. Recent experimental drugs targeting HER2+ breast cancer are summarized in Table 2.

\section{Triterpenoids}

The development of new classes of drugs for the treatment and prevention of HER2+ breast cancer is critical, especially in the clinical setting where resistance is becoming an obstacle. A preclinical class of compounds, the synthetic triterpenoids, has shown promising therapeutic effects against HER2+ breast cancer [96]. Triterpenoids are plant derivatives of which more than 20,000 occur naturally [97]. Two specific triterpenoids which are antitumorigenic in vivo are oleanolic acid (OA) and ursolic acid (UA) [98]. These naturally occurring compounds have been synthetically optimized for many different functions to obtain a variety of synthetic oleanane triterpenoids with various functional groups [98-100]. The use of the 
Table 2 Experimental therapeutic approaches for HER2+ breast cancer

\begin{tabular}{|c|c|c|c|c|}
\hline Strategies and drugs & In vitro HER2 models tested & In vivo HER2 models tested & Treatment and/or prevention & $\operatorname{Ref}(s)$ \\
\hline \multicolumn{5}{|l|}{ Triterpenoids } \\
\hline CDDO & $\begin{array}{l}\text { MCF7 (HER2 transfected); } \\
\text { MDA-MB-435 cells } \\
\text { (HER2 transfected) }\end{array}$ & $\begin{array}{l}\text { MCF7 (HER2 transfected) } \\
\text { cell xenograft }\end{array}$ & Prevention and treatment & [96] \\
\hline CDDO-Me & E-18 cells & MMTV/neu transgenic mice & Prevention and treatment & {$[101,138]$} \\
\hline CDDO-Im & & MMTV/neu transgenic mice & Prevention & {$[102 \bullet]$} \\
\hline \multicolumn{5}{|l|}{ Rexinoids } \\
\hline LG100268 & E-18 cells & MMTV/neu transgenic mice & Prevention and treatment & {$[101,138,140]$} \\
\hline LGD1069 (bexarotene) & & MMTV/neu transgenic mice & Prevention & {$[106,107,141]$} \\
\hline \multicolumn{5}{|l|}{ Vitamin D compounds } \\
\hline BXL0124 & E18-9A-42 cells & MMTV/neu transgenic mice & Prevention & {$[102 \bullet, 111]$} \\
\hline $1 \alpha(\mathrm{OH}) \mathrm{D} 5$ & BT-474 & & Treatment & [112] \\
\hline \multicolumn{5}{|l|}{ Vitamin $\mathrm{E}$ analogs } \\
\hline$\alpha$-TEA & MDA-MB-453 & & Prevention & [114] \\
\hline$\alpha$-TOS & & & Prevention & {$[115]$} \\
\hline Resveratrol & $\begin{array}{l}\text { SK-BR-3 cells; } \mathrm{N} 2 \mathrm{O} 2 \\
\text { murine cells; } 4 \mathrm{~T} 1 \text { cells }\end{array}$ & FVB/N HER2/neu & Prevention and treatment & {$[117,118]$} \\
\hline Genistein & $\begin{array}{l}\text { BT-474; MDA-MB-435 cells } \\
\text { (HER2 transfected); MCF7 } \\
\text { (HER2 transfected) }\end{array}$ & MMTV/neu transgenic mice & Prevention & [120-123] \\
\hline
\end{tabular}

synthetic oleanane, 2-cyano-3, 12-dioxooleana-1, 9-dien-28oic acid (CDDO), has been shown to inhibit cell cycle progression and reduce cyclin D1 levels through increased expression of the cyclin-dependent kinase inhibitor, p21 [96]. CDDO has also been shown to reduce tumor burden, HER2 phosphorylation, and cyclin D1 levels and induce apoptosis in xenograft with MCF-7 cells transfected with ERBB2 [96]. Another synthetic oleanane triterpenoid, CDDO-Me, has been shown to inhibit proliferation and induce apoptosis in E-18 cells and also has reduced the onset of tumors in the mouse mammary tumor virus (MMTV)/neu, transgenic HER2+ mouse model [101]. Studies utilizing the synthetic oleanane triterpenoid, CDDO-Im, demonstrated a delay in mammary tumor onset in the MMTV/neu model [102•]. CDDO-Im decreased the activation of HER2 as well as HER1 and HER3 family members, thus repressing the activation of downstream signaling molecules, Erk1/2 and Akt [102•]. Triterpenoids show growth inhibitory effects in HER2+ breast cancer models, exhibiting the therapeutic potential of these compounds. Triterpenoids can be further explored as combination therapies with other agents or with currently established chemotherapies to fully utilize their anti-HER2 properties.

\section{Rexinoids}

Rexinoids are compounds which bind the three retinoid $\mathrm{X}$ receptors ( $\operatorname{RXR} \alpha, \operatorname{RXR} \beta, \operatorname{RXR} \gamma)$ [103]. The RXRs are nuclear transcription factors that regulate a variety of cellular processes including cell proliferation, differentiation, and apoptosis [104•]. Due to their diverse regulatory potential, RXRs have become a popular target for drug design. One effective rexinoid, LG100268, has been shown to reduce proliferation and induce apoptosis in cells derived from a tumor extracted from a transgenic HER2+ mouse model [101]. LG100268 has shown to be an effective treatment strategy by exhibiting tumor regression of established MMTV/neu tumors in vivo [101]. LG100268 has also proved itself in chemoprevention by inhibiting tumorigenesis in a transgenic model of HER2+ breast cancer [105]. Another rexinoid, LGD1069 (bexarotene), prevented the formation of mammary tumors in a HER2+ mouse model [106]. Bexarotene has also showed promise in combination with a COX-2 inhibitor in a murine model of HER2+ breast cancer [107]. These studies of rexinoids in combination with other therapies show promise in the control of HER2+ breast cancer; however, more extensive combination studies are warranted to uncover the full potential of rexinoids.

\section{Vitamin D Compounds}

Vitamin D analogs have been used in the prevention of breast cancer in various animal models [108-110]. More specifically, the effects of vitamin D and its analogs are being investigated in HER2 + breast cancer models. Treatment with the Gemini vitamin D analog, BXL0124, in the MMTV-ErbB2 transgenic mouse model displayed a reduction in tumor burden [102•, 111]. BXL0124 downregulated HER2 phosphorylation without affecting the total HER2 levels in these mammary tumors. In addition, ERK and AKT phosphorylation were inhibited with BXL0124 treatment [111]. 
Another study investigated the potential of conjugating a vitamin D analog, $1 \alpha(\mathrm{OH}) \mathrm{D} 5$, and HER2-specific antibody to target HER2+ breast cancer [112]. Recent studies show that 25-hydroxy vitamin D supplementation in nonmetastatic HER2+ breast cancer patients was associated with improved disease-free survival [113]. With further confirmation of these studies, vitamin D compounds could hold the capacity to enhance the efficacy of current chemotherapies and HER2+ breast cancer treatments.

\section{Vitamin E Analogs}

Studies have shown that the dietary intake of vitamin E has reduced the risk of developing breast cancer. Recent studies with alpha-tocopheryloxyacetic acid ( $\alpha$-TEA), a novel ether derivative of alpha-tocopherol, suppressed mammary tumor growth and reduced the incidence of lung metastases both in a transplanted and a spontaneous mouse model of breast cancer [114]. Another group showed that $\alpha$-tocopheryl succinate ( $\alpha$-TOS) was capable of inducing apoptosis in HER 2 low and HER2+ cells, suggesting that $\alpha$-TOS could potentially overcome the pro-survival effects of HER2+ breast cancers [115].

\section{Resveratrol}

Resveratrol is a natural polyphenolic compound and has been widely studied for its anticancer properties [116, 117]. One study reported a delayed onset of tumors and reduced metastasis in a murine model of HER2 breast cancer treated with resveratrol [118]. This study also showed that resveratrol reduced HER2 gene expression and induced apoptosis in human and murine cells that overexpress HER2 [118]. Despite numerous studies as a breast cancer chemopreventive compound, resveratrol has not been extensively studied in HER2+ breast cancer and warrants more thorough studies to confirm its effects.

\section{Genistein}

Genistein is the main isoflavone found in soy and has shown to be a potent tyrosine kinase inhibitor [119]. Therefore, it has been studied rather extensively with respect to HER+ breast cancers [120, 121]. MMTV-HER2/neu mice that fed on diets containing genistein demonstrated a significant delay in mammary tumorigenesis [122]. Genistein demonstrated a downregulation of HER2 protein expression and phosphorylation in HER2-overexpressing human breast cancer cells [123]. The photoactivation of psoralen with UVA irradiation, referred to as PUVA, reduced $\mathrm{p} 85^{\mathrm{ErbB} 2}$ phosphorylation leading to tumor cell apoptosis [124]. The use of genistein, flavonoids, or soy products may be potentially beneficial in the prevention of HER2+ breast cancer.

\section{HER2 + Breast Cancer Resistance}

Despite the advancements in therapy for HER2+ breast cancer, trastuzumab resistance has emerged [125]. Since trastuzumab works to inhibit HER2 signaling through various mechanisms, it has been difficult to pinpoint how HER2+ breast cancers develop resistance to this treatment. Several modes of resistance have been elucidated in vitro; however, only some of these have been confirmed in a clinical setting.

A well-studied mechanism for resistance to trastuzumab is the shedding of the extracellular domain of the HER2 receptor, generating a constitutively activated intracellular fragment, known as p95HER2 [126, 127]. This is unable to bind trastuzumab but is still capable of initiating signaling cascades. The trastuzumab-resistant p95HER2 fragment still responds to treatment with lapatinib in vitro since lapatinib specifically targets the kinase activity [127]. This mechanism has been linked to patients with HER2+ metastatic breast cancer in which p95 expression was associated with trastuzumab resistance [127]. Another mechanism of resistance suggests that the HER2trastuzumab interaction is reduced by the increased expression of the membrane-associated glycoprotein, mucin 4 , which competes with trastuzumab for the binding of HER2 [128, 129]. Another mode of resistance is to enhance signaling to evade treatment through the upregulation of the HER3 [130] and insulin-like growth factor 1 receptors (IGF-1R) [125, 131, 132]. Crosstalk between these receptors, as well as other HER family members, can enhance signaling to compensate for signaling lost from trastuzumab treatment [133]. An overexpression of HER family ligands is known to be involved in resistance due to increased receptor dimerization and activation [134]. Downregulation of p27 is known to confer resistance to trastuzumab treatment in vitro [135]. Constitutive activation of PI3K drives cell growth and proliferation and has been implicated as a major mechanism of resistance to trastuzumab [136]. This can occur through decreased levels of PTEN (phosphatase and tensin homologue deleted on chromosome 10) expression, which shows the necessity of PTEN in the mechanism of action of the drug in a clinical setting [137]. Patients with lower PTEN levels showed a decreased response to trastuzumab compared to tumors, which were PTEN-positive [137].

In order to develop more targeted therapies to avoid trastuzumab resistance, there is a need for a better understanding of how these pathways work, especially in the clinical realm. For this reason, the area of HER2-targeted therapies and chemoprevention still remains a vital area of breast cancer research.

\section{Future Therapies}

There are many new agents on the horizon, which include new and modified antibodies, tyrosine kinase 
inhibitors, vaccines, as well as natural product derivatives that target the HER2 receptor and its associated pathways [31, 138]. Although HER2 is the direct target of many of these new treatment options, other therapeutics that are being developed which indirectly target HER2 signaling by focusing on other molecules involved in the process, such as mTOR, IGF-1R, HSP90, and VEGF, are also under investigation [31]. These new treatment strategies, along with existing regiments, will help to overcome the resistance associated with trastuzumab treatment. Many of these new drugs are being clinically evaluated in a combination approach or alongside currently approved therapies.

\section{Conclusions}

HER2, a common subtype of breast cancer, is overexpressed in approximately $20-30 \%$ of cases, making it a significant therapeutic target for breast cancer. The family of HER receptors controls antiapoptotic pathways as well as proliferation mechanisms through the MAPK and PI3K/Akt pathways. Overexpression of the HER2 receptor allows for the upregulation of these pathways leading to breast cancer. The breadth of knowledge in the area of HER2 signaling has expanded greatly since its first implication in breast cancer nearly three decades ago. Despite advances in HER2+ breast cancer therapy, resistance to commonly utilized drugs has emerged. To combat this, there is a vast array of new drugs and combination therapies being evaluated clinically and preclinically. Among new treatments, various dietary phytochemicals have shown promise for the prevention and therapy of HER2+ breast cancer. An increased understanding of HER2 signaling pathways as well as novel in vivo and in vitro models to study resistance will provide a greater insight into the mechanisms of disease in HER2+ breast cancer. This ongoing research is vital to identify new therapeutic targets and develop chemopreventive agents to better target HER2+ breast cancer.

Financial Support This work was supported in part by the National Institutes of Health National Cancer Institute R01 AT007036, R01 CA127645 and the National Institute of Environmental Health Sciences Grant ES005022, and the Trustees Research Fellowship Program at Rutgers, The State University of New Jersey.

\section{Compliance with Ethics Guidelines}

Conflict of Interest Joseph Wahler and Nanjoo Suh declare that they have no conflict of interest.

Human and Animal Rights and Informed Consent This article does not contain any studies with human or animal subjects performed by any of the authors.

\section{References}

Papers of particular interest, published recently, have been highlighted as:

- Of importance

- Of major importance

1. Siegel R, Ma J, Zou Z, Jemal A. Cancer statistics, 2014. CA Cancer J Clin. 2014;64(1):9-29.

2. Prat A, Perou CM. Deconstructing the molecular portraits of breast cancer. Mol Oncol. 2011;5(1):5-23.

3. Ross JS, Slodkowska EA, Symmans WF, Pusztai L, Ravdin PM, Hortobagyi GN. The HER-2 receptor and breast cancer: ten years of targeted anti-HER-2 therapy and personalized medicine. Oncologist. 2009;14(4):320-68.

4. Hynes NE, Lane HA. ERBB receptors and cancer: the complexity of targeted inhibitors. Nat Rev Cancer. 2005;5(5):341-54.

5. Yarden Y, Sliwkowski MX. Untangling the ErbB signalling network. Nat Rev Mol Cell Biol. 2001;2(2):127-37.

6. Arteaga CL. Epidermal growth factor receptor dependence in human tumors: more than just expression? Oncologist. 2002;7 Suppl 4:31-9.

7. O'Neill F, Madden SF, Aherne ST, et al. Gene expression changes as markers of early lapatinib response in a panel of breast cancer cell lines. Mol Cancer. 2012;11:41.

8. Hudis CA. Trastuzumab - mechanism of action and use in clinical practice. N Engl J Med. 2007;357(1):39-51.

9. Howe LR, Brown PH. Targeting the HER/EGFR/ErbB family to prevent breast cancer. Cancer Prev Res. 2011;4(8):1149-57.

10. Nahta R, Hung MC, Esteva FJ. The HER-2-targeting antibodies trastuzumab and pertuzumab synergistically inhibit the survival of breast cancer cells. Cancer Res. 2004;64(7):2343-6.

11. Tevaarwerk AJ, Kolesar JM. Lapatinib: a small-molecule inhibitor of epidermal growth factor receptor and human epidermal growth factor receptor- 2 tyrosine kinases used in the treatment of breast cancer. Clin Ther. 2009;31(Pt 2):2332-48.

12. Gori S, Montemurro F, Spazzapan S, et al. Retreatment with trastuzumab-based therapy after disease progression following lapatinib in HER2-positive metastatic breast cancer. Ann Oncol Off J Eur Soc Med OncoL ESMO. 2012;23(6):1436-41.

13. Montemurro F, Donadio M, Clavarezza M, et al. Outcome of patients with HER2-positive advanced breast cancer progressing during trastuzumab-based therapy. Oncologist. 2006;11(4):31824.

14. Diermeier S, Horvath G, Knuechel-Clarke R, Hofstaedter F, Szollosi J, Brockhoff G. Epidermal growth factor receptor coexpression modulates susceptibility to herceptin in HER2/neu overexpressing breast cancer cells via specific erbB-receptor interaction and activation. Exp Cell Res. 2005;304(2):604-19.

15. Strecker TE, Shen Q, Zhang Y, et al. Effect of lapatinib on the development of estrogen receptor-negative mammary tumors in mice. J Natl Cancer Inst. 2009;101(2):107-13.

16. Yarden Y, Pines G. The ERBB network: at last, cancer therapy meets systems biology. Nat Rev Cancer. 2012;12(8):553-63.

17. Slamon DJ, Leyland-Jones B, Shak S, et al. Use of chemotherapy plus a monoclonal antibody against HER2 for metastatic breast cancer that overexpresses HER2. N Engl J Med. 2001;344(11): 783-92.

18. Pegram MD, Konecny G, Slamon DJ. The molecular and cellular biology of HER2/neu gene amplification/overexpression and the clinical development of herceptin (trastuzumab) therapy for breast cancer. Cancer Treat Res. 2000;103:57-75.

19. Garrett TP, McKern NM, Lou M, et al. Crystal structure of a truncated epidermal growth factor receptor extracellular domain 
bound to transforming growth factor alpha. Cell. 2002;110(6): $763-73$.

20. Ogiso H, Ishitani R, Nureki O, et al. Crystal structure of the complex of human epidermal growth factor and receptor extracellular domains. Cell. 2002;110(6):775-87.

21. Bange J, Zwick E, Ullrich A. Molecular targets for breast cancer therapy and prevention. Nat Med. 2001;7(5):548-52.

22. Sliwkowski MX. Ready to partner. Nat Struct Biol. 2003;10(3): 158-9.

23. Graus-Porta D, Beerli RR, Daly JM, Hynes NE. ErbB-2, the preferred heterodimerization partner of all ErbB receptors, is a mediator of lateral signaling. EMBO J. 1997;16(7):1647-55.

24. Guy PM, Platko JV, Cantley LC, Cerione RA, Carraway 3rd KL. Insect cell-expressed p180erbB3 possesses an impaired tyrosine kinase activity. Proc Natl Acad Sci U S A. 1994;91(17):8132-6.

25. Knighton DR, Cadena DL, Zheng J, et al. Structural features that specify tyrosine kinase activity deduced from homology modeling of the epidermal growth factor receptor. Proc Natl Acad Sci U S A. 1993;90(11):5001-5

26. Citri A, Skaria KB, Yarden Y. The deaf and the dumb: the biology of ErbB-2 and ErbB-3. Exp Cell Res. 2003;284(1):54-65.

27. Yarden Y, Schlessinger J. Epidermal growth factor induces rapid, reversible aggregation of the purified epidermal growth factor receptor. Biochemistry. 1987;26(5):1443-51.

28. Kokai Y, Myers JN, Wada T, et al. Synergistic interaction of p185c-neu and the EGF receptor leads to transformation of rodent fibroblasts. Cell. 1989;58(2):287-92.

29. Hirata A, Ogawa S, Kometani T, et al. ZD1839 (Iressa) induces antiangiogenic effects through inhibition of epidermal growth factor receptor tyrosine kinase. Cancer Res. 2002;62(9):2554-60.

30. Huang GC, Hobbs S, Walton M, Epstein RJ. Dominant negative knockout of p53 abolishes ErbB2-dependent apoptosis and permits growth acceleration in human breast cancer cells. $\mathrm{Br} \mathrm{J}$ Cancer. 2002;86(7):1104-9.

31. Arteaga CL, Sliwkowski MX, Osborne CK, Perez EA, Puglisi F, Gianni L. Treatment of HER2-positive breast cancer: current status and future perspectives. Nat Rev Clin Oncol. 2012;9(1):16-32.

32. Alimandi M, Romano A, Curia MC, et al. Cooperative signaling of ErbB3 and ErbB2 in neoplastic transformation and human mammary carcinomas. Oncogene. 1995;10(9):1813-21.

33. Wallasch C, Weiss FU, Niederfellner G, Jallal B, Issing W, Ullrich A. Heregulin-dependent regulation of HER2/neu oncogenic signaling by heterodimerization with HER3. EMBO J. 1995;14(17): 4267-75.

34. Fendly BM, Winget M, Hudziak RM, Lipari MT, Napier MA, Ullrich A. Characterization of murine monoclonal antibodies reactive to either the human epidermal growth factor receptor or HER2/neu gene product. Cancer Res. 1990;50(5):1550-8.

35. Hudziak RM, Lewis GD, Winget M, Fendly BM, Shepard HM, Ullrich A. p185HER2 monoclonal antibody has antiproliferative effects in vitro and sensitizes human breast tumor cells to tumor necrosis factor. Mol Cell Biol. 1989;9(3):1165-72.

36. Carter P, Presta L, Gorman CM, et al. Humanization of an antip185HER2 antibody for human cancer therapy. Proc Natl Acad Sci U S A. 1992;89(10):4285-9.

37. Baselga J, Tripathy D, Mendelsohn J, et al. Phase II study of weekly intravenous recombinant humanized anti-p185HER2 monoclonal antibody in patients with HER2/neu-overexpressing metastatic breast cancer. J Clin Oncol Off J Am Soc Clin Oncol. 1996;14(3):737-44.

38. Cho HS, Mason K, Ramyar KX, et al. Structure of the extracellular region of HER2 alone and in complex with the herceptin fab. Nature. 2003;421(6924):756-60.

39. Yakes FM, Chinratanalab W, Ritter CA, King W, Seelig S, Arteaga CL. Herceptin-induced inhibition of phosphatidylinositol-3 kinase and Akt Is required for antibody-mediated effects on p27, cyclin D1, and antitumor action. Cancer Res. 2002;62(14):4132-41.

40. Holbro T, Civenni G, Hynes NE. The ErbB receptors and their role in cancer progression. Exp Cell Res. 2003;284(1):99-110.

41. Molina MA, Codony-Servat J, Albanell J, Rojo F, Arribas J, Baselga J. Trastuzumab (herceptin), a humanized anti-Her2 receptor monoclonal antibody, inhibits basal and activated Her2 ectodomain cleavage in breast cancer cells. Cancer Res. 2001;61(12):4744-9.

42. Mohsin SK, Weiss HL, Gutierrez MC, et al. Neoadjuvant trastuzumab induces apoptosis in primary breast cancers. J Clin Oncol Off J Am Soc Clin Oncol. 2005;23(11):2460-8.

43. Kostler WJ, Schwab B, Singer CF, et al. Monitoring of serum Her$2 /$ neu predicts response and progression-free survival to trastuzumab-based treatment in patients with metastatic breast cancer. Clin Cancer Res Off J Am Assoc Cancer Res. 2004;10(5):1618-24.

44. Hortobagyi GN. Trastuzumab in the treatment of breast cancer. N Engl J Med. 2005;353(16):1734-6.

45. Yin W, Jiang Y, Shen Z, Shao Z, Lu J. Trastuzumab in the adjuvant treatment of HER2-positive early breast cancer patients: a metaanalysis of published randomized controlled trials. PLoS ONE. 2011;6(6):e21030.

46. Cobleigh MA, Vogel CL, Tripathy D, et al. Multinational study of the efficacy and safety of humanized anti-HER 2 monoclonal antibody in women who have HER2-overexpressing metastatic breast cancer that has progressed after chemotherapy for metastatic disease. J Clin Oncol Off J Am Soc Clin Oncol. 1999;17(9): 2639-48.

47. Baselga J, Norton L, Albanell J, Kim YM, Mendelsohn J. Recombinant humanized anti-HER2 antibody (Herceptin) enhances the antitumor activity of paclitaxel and doxorubicin against HER2/neu overexpressing human breast cancer xenografts. Cancer Res. 1998;58(13):2825-31.

48. Pegram MD. Docetaxel and herceptin: foundation for future strategies. Oncologist. 2001;6 Suppl 3:22-5.

49. Marty M, Cognetti F, Maraninchi D, et al. Randomized phase II trial of the efficacy and safety of trastuzumab combined with docetaxel in patients with human epidermal growth factor receptor 2positive metastatic breast cancer administered as first-line treatment: the M77001 study group. J Clin Oncol Off J Am Soc Clin Oncol. 2005;23(19):4265-74

50. Tripathy D, Slamon DJ, Cobleigh M, et al. Safety of treatment of metastatic breast cancer with trastuzumab beyond disease progression. J Clin Oncol Off J Am Soc Clin Oncol. 2004;22(6):1063-70.

51. Franklin MC, Carey KD, Vajdos FF, Leahy DJ, de Vos AM, Sliwkowski MX. Insights into ErbB signaling from the structure of the ErbB2-pertuzumab complex. Cancer Cell. 2004;5(4):31728.

52. Agus DB, Akita RW, Fox WD, et al. Targeting ligand-activated ErbB2 signaling inhibits breast and prostate tumor growth. Cancer Cell. 2002;2(2):127-37.

53. Scheuer W, Friess T, Burtscher H, Bossenmaier B, Endl J, Hasmann M. Strongly enhanced antitumor activity of trastuzumab and pertuzumab combination treatment on HER2-positive human xenograft tumor models. Cancer Res. 2009;69(24):9330-6.

54.• Baselga J, Cortes J, Kim SB, et al. Pertuzumab plus trastuzumab plus docetaxel for metastatic breast cancer. N Engl J Med. 2012;366(2):109-19. This clinical trial was one of the first to demonstrate the use of multiple HER2+ targeted therapies to effectively treat advanced HER2+ breast cancer.

55. Baselga J, Gelmon KA, Verma S, et al. Phase II trial of pertuzumab and trastuzumab in patients with human epidermal growth factor receptor 2-positive metastatic breast cancer that progressed during prior trastuzumab therapy. J Clin Oncol Off $\mathrm{J}$ Am Soc Clin Oncol. 2010;28(7):1138-44. 
56. Baselga J, Swain SM. CLEOPATRA: a phase III evaluation of pertuzumab and trastuzumab for HER2-positive metastatic breast cancer. Clin Breast Cancer. 2010;10(6):489-91.

57. Cortes J, Fumoleau P, Bianchi GV, et al. Pertuzumab monotherapy after trastuzumab-based treatment and subsequent reintroduction of trastuzumab: activity and tolerability in patients with advanced human epidermal growth factor receptor 2-positive breast cancer. J Clin Oncol Off J Am Soc Clin Oncol. 2012;30(14):1594-600.

58. Portera CC, Walshe JM, Rosing DR, et al. Cardiac toxicity and efficacy of trastuzumab combined with pertuzumab in patients with [corrected] human epidermal growth factor receptor 2positive metastatic breast cancer. Clin Cancer Res Off J Am Assoc Cancer Res. 2008;14(9):2710-6.

59. Lu D, Burris Iii HA, Wang B, et al. Drug interaction potential of trastuzumab emtansine (T-DM1) combined with pertuzumab in patients with HER2-positive metastatic breast cancer. Curr Drug Metab. 2012;13(7):911-22.

60. Lewis Phillips GD, Li G, Dugger DL, et al. Targeting HER2positive breast cancer with trastuzumab-DM1, an antibodycytotoxic drug conjugate. Cancer Res. 2008;68(22):9280-90.

61. Niculescu-Duvaz I. Trastuzumab emtansine, an antibody-drug conjugate for the treatment of HER2+ metastatic breast cancer. Curr Opin Mol Ther. 2010;12(3):350-60.

62. Teicher BA, Doroshow JH. The promise of antibody-drug conjugates. N Engl J Med. 2012;367(19):1847-8. This article reviews the role and importance of antibody drug conjugates, such as T-DM1, in the overall improvement of cancer therapies.

63. Junttila TT, Li G, Parsons K, Phillips GL, Sliwkowski MX. Trastuzumab-DM1 (T-DM1) retains all the mechanisms of action of trastuzumab and efficiently inhibits growth of lapatinib insensitive breast cancer. Breast Cancer Res Treat. 2011;128(2):34756.

64.•• Diessner J, Bruttel V, Stein RG, et al. Targeting of preexisting and induced breast cancer stem cells with trastuzumab and trastuzumab emtansine (T-DM1). Cell Death Dis. 2014;5:e1149. This study is one of the first to investigate the effectiveness of current HER2 + therapies to target breast cancer stem cells.

65. Verma S, Miles D, Gianni L, et al. Trastuzumab emtansine for HER2-positive advanced breast cancer. N Engl J Med. 2012;367(19):1783-91.

66. Krop IE, LoRusso P, Miller KD, et al. A phase II study of trastuzumab emtansine in patients with human epidermal growth factor receptor 2-positive metastatic breast cancer who were previously treated with trastuzumab, lapatinib, an anthracycline, a taxane, and capecitabine. J Clin Oncol Off J Am Soc Clin Oncol. 2012;30(26):3234-41. This clinical study is critical in overcoming breast cancer resistance to current HER2 + therapies through more targeted approached, such as antibody linked therapies.

67. Burris 3rd HA, Hurwitz HI, Dees EC, et al. Phase I safety, pharmacokinetics, and clinical activity study of lapatinib (GW572016), a reversible dual inhibitor of epidermal growth factor receptor tyrosine kinases, in heavily pretreated patients with metastatic carcinomas. J Clin Oncol Off J Am Soc Clin Oncol. 2005;23(23):5305-13

68. Wood ER, Truesdale AT, McDonald OB, et al. A unique structure for epidermal growth factor receptor bound to GW572016 (Lapatinib): relationships among protein conformation, inhibitor off-rate, and receptor activity in tumor cells. Cancer Res. 2004;64(18):6652-9.

69. Geyer CE, Forster J, Lindquist D, et al. Lapatinib plus capecitabine for HER2-positive advanced breast cancer. N Engl J Med. 2006;355(26):2733-43.

70. Ryan Q, Ibrahim A, Cohen MH, et al. FDA drug approval summary: lapatinib in combination with capecitabine for previously treated metastatic breast cancer that overexpresses HER-2. Oncologist. 2008;13(10):1114-9.

71. Johnston S, Pippen Jr J, Pivot X, et al. Lapatinib combined with letrozole versus letrozole and placebo as first-line therapy for postmenopausal hormone receptor-positive metastatic breast cancer. J Clin Oncol Off J Am Soc Clin Oncol. 2009;27(33):5538-46.

72. Riemsma R, Forbes CA, Amonkar MM, et al. Systematic review of lapatinib in combination with letrozole compared with other first-line treatments for hormone receptor positive $(\mathrm{HR}+)$ and HER2+ advanced or metastatic breast cancer(MBC). Curr Med Res Opin. 2012;28(8):1263-79.

73. Blackwell KL, Pegram MD, Tan-Chiu E, et al. Single-agent lapatinib for HER2-overexpressing advanced or metastatic breast cancer that progressed on first- or second-line trastuzumab-containing regimens. Ann Oncol Off J Eur Soc Med Oncol ESMO. 2009;20(6):1026-31.

74. Rusnak DW, Lackey K, Affleck K, et al. The effects of the novel, reversible epidermal growth factor receptor/ErbB-2 tyrosine kinase inhibitor, GW2016, on the growth of human normal and tumor-derived cell lines in vitro and in vivo. Mol Cancer Ther. 2001;1(2):85-94.

75. Konecny GE, Pegram MD, Venkatesan N, et al. Activity of the dual kinase inhibitor lapatinib (GW572016) against HER-2overexpressing and trastuzumab-treated breast cancer cells. Cancer Res. 2006;66(3):1630-9.

76. Xia W, Mullin RJ, Keith BR, et al. Anti-tumor activity of GW572016: a dual tyrosine kinase inhibitor blocks EGF activation of EGFR/erbB2 and downstream Erk1/2 and AKT pathways. Oncogene. 2002;21(41):6255-63.

77. O'Donovan N, Byrne AT, O'Connor AE, McGee S, Gallagher WM, Crown J. Synergistic interaction between trastuzumab and EGFR/HER-2 tyrosine kinase inhibitors in HER-2 positive breast cancer cells. Investig New Drugs. 2011;29(5):752-9.

78. Xia W, Gerard CM, Liu L, Baudson NM, Ory TL, Spector NL. Combining lapatinib (GW572016), a small molecule inhibitor of ErbB1 and ErbB2 tyrosine kinases, with therapeutic anti-ErbB2 antibodies enhances apoptosis of ErbB2-overexpressing breast cancer cells. Oncogene. 2005;24(41):6213-21.

79. Blackwell KL, Burstein HJ, Storniolo AM, et al. Randomized study of lapatinib alone or in combination with trastuzumab in women with ErbB2-positive, trastuzumab-refractory metastatic breast cancer. J Clin Oncol Off J A Soc Clin Oncol. 2010;28(7): 1124-30.

80. Baselga J, Bradbury I, Eidtmann H, et al. Lapatinib with trastuzumab for HER2-positive early breast cancer (NeoALTTO): a randomised, open-label, multicentre, phase 3 trial. Lancet. 2012;379(9816):633-40.

81. Moy B, Goss PE. TEACH: Tykerb evaluation after chemotherapy. Clin Beast Cancer. 2007;7(6):489-92.

82. Burstein HJ, Sun Y, Dirix LY, et al. Neratinib, an irreversible ErbB receptor tyrosine kinase inhibitor, in patients with advanced ErbB2-positive breast cancer. J Clin Oncol Off J Am Soc Clin Oncol. 2010;28(8):1301-7.

83. Rabindran SK, Discafani CM, Rosfjord EC, et al. Antitumor activity of HKI-272, an orally active, irreversible inhibitor of the HER-2 tyrosine kinase. Cancer Res. 2004;64(11):3958-65.

84. Canonici A, Gijsen M, Mullooly M, et al. Neratinib overcomes trastuzumab resistance in HER2 amplified breast cancer. Oncotarget. 2013. This study investigates the potential of new therapies to overcome resistance to current HER2 + therapies.

85. Tsang RY, Finn RS. Beyond trastuzumab: novel therapeutic strategies in HER2-positive metastatic breast cancer. $\mathrm{Br} \mathrm{J}$ Cancer. 2012;106(1):6-13.

86. Lin NU, Winer EP, Wheatley D, et al. A phase II study of afatinib (BIBW 2992), an irreversible ErbB family blocker, in patients with HER2-positive metastatic breast cancer progressing after 
trastuzumab. Breast Cancer Res Treat. 2012;133(3):1057-65. The clinical trial shows promise of new therapies to effectively treat HER2+ breast cancer that has escaped trastuzumab treatment.

87. Ring A, Wheatley D, Hatcher H, et al. Phase I study to assess the combination of afatinib with trastuzumab in patients with advanced or metastatic HER2-positive breast cancer. Clin Cancer Res Off J Am Assoc Cancer Res. 2014.

88. Brockhoff G, Heiss P, Schlegel J, Hofstaedter F, Knuechel R. Epidermal growth factor receptor, c-erbB2 and c-erbB3 receptor interaction, and related cell cycle kinetics of SK-BR-3 and BT474 breast carcinoma cells. Cytometry. 2001;44(4):338-48.

89. Barok M, Isola J, Palyi-Krekk Z, et al. Trastuzumab causes antibody-dependent cellular cytotoxicity-mediated growth inhibition of submacroscopic JIMT-1 breast cancer xenografts despite intrinsic drug resistance. Mol Cancer Ther. 2007;6(7):2065-72.

90. Tanner M, Kapanen AI, Junttila T, et al. Characterization of a novel cell line established from a patient with Herceptin-resistant breast cancer. Mol Cancer Ther. 2004;3(12):1585-92.

91. Ginestier C, Adelaide J, Goncalves A, et al. ERBB2 phosphorylation and trastuzumab sensitivity of breast cancer cell lines. Oncogene. 2007;26(50):7163-9.

92. Guy CT, Webster MA, Schaller M, Parsons TJ, Cardiff RD, Muller WJ. Expression of the neu protooncogene in the mammary epithelium of transgenic mice induces metastatic disease. Proc Natl Acad Sci U S A. 1992;89(22):10578-82.

93. Green JE, Hudson T. The promise of genetically engineered mice for cancer prevention studies. Nat Rev Cancer. 2005;5(3):184-98.

94. Cardiff RD, Wellings SR. The comparative pathology of human and mouse mammary glands. J Mammary Gland Biol Neoplasia. 1999;4(1):105-22.

95. Cardiff RD, Anver MR, Gusterson BA, et al. The mammary pathology of genetically engineered mice: the consensus report and recommendations from the Annapolis meeting. Oncogene. 2000;19(8):968-88.

96. Konopleva M, Zhang W, Shi YX, et al. Synthetic triterpenoid 2cyano-3,12-dioxooleana-1,9-dien-28-oic acid induces growth arrest in HER2-overexpressing breast cancer cells. Mol Cancer Ther. 2006;5(2):317-28.

97. Phillips DR, Rasbery JM, Bartel B, Matsuda SP. Biosynthetic diversity in plant triterpene cyclization. Curr Opin Plant Biol. 2006;9(3):305-14.

98. Dzubak P, Hajduch M, Vydra D, et al. Pharmacological activities of natural triterpenoids and their therapeutic implications. Nat Prod Rep. 2006;23(3):394-411.

99. Connolly JD, Hill RA. Triterpenoids. Nat Prod Rep. 2005;22(4): 487-503.

100. Honda T, Rounds BV, Bore L, et al. Synthetic oleanane and ursane triterpenoids with modified rings $\mathrm{A}$ and $\mathrm{C}$ : a series of highly active inhibitors of nitric oxide production in mouse macrophages. J Med Chem. 2000;43(22):4233-46.

101. Liby K, Risingsong R, Royce DB, et al. Prevention and treatment of experimental estrogen receptor-negative mammary carcinogenesis by the synthetic triterpenoid CDDO-methyl ester and the rexinoid LG100268. Clin Cancer Res Off J Am Assoc Cancer Res. 2008;14(14):4556-63.

102. So JY, Wahler JE, Yoon T, et al. Oral administration of a Gemini vitamin $\mathrm{D}$ analog, a synthetic triterpenoid and the combination prevents mammary tumorigenesis driven by ErbB2 overexpression. Cancer Prev Res. 2013;6(9):959-70. This study is one of the first to investigate the combination of chemopreventive agents to target HER2+ breast cancer.

103. Germain P, Chambon P, Eichele G, et al. International union of pharmacology. LXIII. Retinoid X receptors. Pharmacol Rev. 2006;58(4):760-72.
104. Maire A, Alvarez S, Shankaranarayanan P, Lera AR, Bourguet W, Gronemeyer H. Retinoid receptors and therapeutic applications of RAR/RXR modulators. Curr Top Med Chem. 2012;12(6):505-27. This review summarizes the potential of rexinoid therapies as a novel approach to treat disease, such as HER2+ breast cancer.

105. Li Y, Zhang Y, Hill J, et al. The rexinoid LG100268 prevents the development of preinvasive and invasive estrogen receptor negative tumors in MMTV-erbB2 mice. Clin Cancer Res Off J Am Assoc Cancer Res. 2007;13(20):6224-31.

106. Wu K, Zhang Y, Xu XC, et al. The retinoid X receptor-selective retinoid, LGD1069, prevents the development of estrogen receptor-negative mammary tumors in transgenic mice. Cancer Res. 2002;62(22):6376-80.

107. Brown PH, Subbaramaiah K, Salmon AP, et al. Combination chemoprevention of HER2/neu-induced breast cancer using a cyclooxygenase- 2 inhibitor and a retinoid $\mathrm{X}$ receptor-selective retinoid. Cancer Prev Res. 2008;1(3):208-14.

108. Jacobson EA, James KA, Newmark HL, Carroll KK. Effects of dietary fat, calcium, and vitamin $\mathrm{D}$ on growth and mammary tumorigenesis induced by 7,12-dimethylbenz(a)anthracene in female Sprague-Dawley rats. Cancer Res. 1989;49(22):6300-3.

109. Mehta R, Hawthorne M, Uselding L, et al. Prevention of Nmethyl-N-nitrosourea-induced mammary carcinogenesis in rats by 1 alpha-hydroxyvitamin $\mathrm{D}(5)$. J Natl Cancer Inst. 2000;92(22):1836-40

110. Anzano MA, Smith JM, Uskokovic MR, et al. 1 alpha,25Dihydroxy-16-ene-23-yne-26,27-hexa fluorocholecalciferol (Ro24-5531), a new deltanoid (vitamin D analogue) for prevention of breast cancer in the rat. Cancer Res. 1994;54(7):1653-6.

111. Lee HJ, So JY, DeCastro A, et al. Gemini vitamin D analog suppresses ErbB2-positive mammary tumor growth via inhibition of ErbB2/AKT/ERK signaling. J Steroid Biochem Mol Biol. 2010;121(1-2):408-12.

112. Punj V, Graves JM, Mehta RR. Effect of vitamin D analog (1alpha hydroxy D5) immunoconjugated to Her-2 antibody on breast cancer. Int J Cancer. 2004;108(6):922-9.

113. Zeichner SB, Koru-Sengul T, Shah N, et al. Improved clinical outcomes associated with vitamin D supplementation during adjuvant chemotherapy in patients with HER2 nonmetastatic breast cancer. Clin Breast Cancer. 2014.

114. Hahn T, Bradley-Dunlop DJ, Hurley LH, et al. The vitamin E analog, alpha-tocopheryloxyacetic acid enhances the anti-tumor activity of trastuzumab against HER2/neu-expressing breast cancer. BMC Cancer. 2011;11:471

115. Wang XF, Witting PK, Salvatore BA, Neuzil J. Vitamin E analogs trigger apoptosis in HER2/erbB2-overexpressing breast cancer cells by signaling via the mitochondrial pathway. Biochem Bioph Res Commun. 2005;326(2):282-9.

116. Aluyen JK, Ton QN, Tran T, Yang AE, Gottlieb HB, Bellanger RA. Resveratrol: potential as anticancer agent. J Diet Suppl. 2012;9(1):45-56.

117. Whitlock NC, Baek SJ. The anticancer effects of resveratrol: modulation of transcription factors. Nutr Cancer. 2012;64(4):493-502.

118. Provinciali M, Re F, Donnini A, et al. Effect of resveratrol on the development of spontaneous mammary tumors in HER-2/neu transgenic mice. Int J Cancer. 2005;115(1):36-45.

119. Akiyama T, Ishida J, Nakagawa S, et al. Genistein, a specific inhibitor of tyrosine-specific protein kinases. J Biol Chem. 1987;262(12):5592-5.

120. Li Y, Bhuiyan M, Sarkar FH. Induction of apoptosis and inhibition of c-erbB-2 in MDA-MB-435 cells by genistein. Int J Oncol. 1999;15(3):525-33.

121. Peng JH, Zhu JD, Mi MT, et al. Prepubertal genistein exposure affects erbB2/Akt signal and reduces rat mammary tumorigenesis. 
Eur J Cancer Prev the Off J Eur Cancer Prev Organ. 2010;19(2): $110-9$.

122. Jin Z, MacDonald RS. Soy isoflavones increase latency of spontaneous mammary tumors in mice. J Nutr. 2002;132(10):3186-90.

123. Sakla MS, Shenouda NS, Ansell PJ, Macdonald RS, Lubahn DB. Genistein affects HER2 protein concentration, activation, and promoter regulation in BT-474 human breast cancer cells. Endocrine. 2007;32(1):69-78.

124. Xia W, Gooden D, Liu L, et al. Photo-activated psoralen binds the ErbB2 catalytic kinase domain, blocking ErbB2 signaling and triggering tumor cell apoptosis. PLoS ONE. 2014;9(2):e88983.

125. Nahta R, Yu D, Hung MC, Hortobagyi GN, Esteva FJ. Mechanisms of disease: understanding resistance to HER2-targeted therapy in human breast cancer. Nat Clin Pract Oncol. 2006;3(5):269-80.

126. Saez R, Molina MA, Ramsey EE, et al. p95HER-2 predicts worse outcome in patients with HER-2-positive breast cancer. Clin Cancer Res Off J Am Assoc Cancer Res. 2006;12(2):424-31.

127. Scaltriti M, Rojo F, Ocana A, et al. Expression of p95HER2, a truncated form of the HER2 receptor, and response to anti-HER2 therapies in breast cancer. J Natl Cancer Inst. 2007;99(8):628-38.

128. Nagy P, Friedlander E, Tanner M, et al. Decreased accessibility and lack of activation of ErbB2 in JIMT-1, a herceptin-resistant, MUC4expressing breast cancer cell line. Cancer Res. 2005;65(2):473-82.

129. Price-Schiavi SA, Jepson S, Li P, et al. Rat Muc4 (sialomucin complex) reduces binding of anti-ErbB2 antibodies to tumor cell surfaces, a potential mechanism for herceptin resistance. Int $\mathrm{J}$ Cancer. 2002;99(6):783-91.

130. Sergina NV, Rausch M, Wang D, et al. Escape from HER-family tyrosine kinase inhibitor therapy by the kinase-inactive HER3. Nature. 2007;445(7126):437-41.

131. Lu Y, Zi X, Zhao Y, Mascarenhas D, Pollak M. Insulin-like growth factor-I receptor signaling and resistance to trastuzumab (Herceptin). J Natl Cancer Inst. 2001;93(24):1852-7.

132. Nahta R, Yuan LX, Zhang B, Kobayashi R, Esteva FJ. Insulin-like growth factor-I receptor/human epidermal growth factor receptor 2 heterodimerization contributes to trastuzumab resistance of breast cancer cells. Cancer Res. 2005;65(23):11118-28.

133. Ritter CA, Perez-Torres M, Rinehart C, et al. Human breast cancer cells selected for resistance to trastuzumab in vivo overexpress epidermal growth factor receptor and ErbB ligands and remain dependent on the ErbB receptor network. Clin Cancer Res Off J Am Assoc Cancer Res. 2007;13(16): 4909-19.

134. Valabrega G, Montemurro F, Sarotto I, et al. TGFalpha expression impairs trastuzumab-induced HER2 downregulation. Oncogene. 2005;24(18):3002-10.

135. Nahta R, Takahashi T, Ueno NT, Hung MC, Esteva FJ. P27(kip1) down-regulation is associated with trastuzumab resistance in breast cancer cells. Cancer Res. 2004;64(11): 3981-6.

136. Berns K, Horlings HM, Hennessy BT, et al. A functional genetic approach identifies the PI3K pathway as a major determinant of trastuzumab resistance in breast cancer. Cancer Cell. 2007;12(4): 395-402.

137. Nagata Y, Lan KH, Zhou X, et al. PTEN activation contributes to tumor inhibition by trastuzumab, and loss of PTEN predicts trastuzumab resistance in patients. Cancer Cell. 2004;6(2):117-27.

138. Liby KT, Yore MM, Sporn MB. Triterpenoids and rexinoids as multifunctional agents for the prevention and treatment of cancer. Nat Rev Cancer. 2007;7(5):357-69.

139.• Andre F, O'Regan R, Ozguroglu M, et al. Everolimus for women with trastuzumab-resistant, HER2-positive, advanced breast cancer (BOLERO-3): a randomised, double-blind, placebo-controlled phase 3 trial. Lancet Oncol. 2014;15(6):580-91. This clinical trial demonstrates the potential of therapies that do not directly affect the HER2 receptor, but rather downstream signaling involved in the HER2 signaling cascade.

140. Liby K, Rendi M, Suh N, et al. The combination of the rexinoid, LG100268, and a selective estrogen receptor modulator, either arzoxifene or acolbifene, synergizes in the prevention and treatment of mammary tumors in an estrogen receptor-negative model of breast cancer. Clin Cancer Res Off J Am Assoc Cancer Res. 2006;12(19):5902-9.

141. Kong G, Kim HT, Wu K, et al. The retinoid X receptor-selective retinoid, LGD1069, down-regulates cyclooxygenase-2 expression in human breast cells through transcription factor crosstalk: implications for molecular-based chemoprevention. Cancer Res. 2005;65(8):3462-9. 